\title{
论建筑施工工程的质量管理与控制
}

\author{
刘守勇 \\ 北京建工集团有限责任公司，北京 100055
}

[摘要] 在社会飞速发展的影响下, 使得我国各个行业都得到了显著的进步发展, 从而促进了我国综合国力的提升, 这样就为 我国城市化建设工作带来了良好的机遇。就现如今我国城市化建设工作的实际情况来说，最为突出的特征就是农村人员逐渐 转移到城市, 这样加剧了城市住房的压力, 为了更好的满足人们对住房的需求, 大量的建筑工程应时而生, 并且建筑工程结 构正在朝着大规模、综合性的方向迈进。与此同时, 民众生活质量和生活观念也发生了明显的变化, 人们对建筑工程的质量 提出了更高的要求。但是就建筑工程施工实际情况来说, 大部分的施工单位为了追求更多的经济收益, 往往会选择成本低、 施工效率高的建筑施工模式, 这样对于建筑工程施工质量的保证是非常不利的, 所以我们还需要加大力度实施建筑工程质量 管理和控制工作, 这篇文章主要针对建筑施工工程的质量管理与控制工作展开全面深入的研究分析, 并针对其中所存在的各 类问题提出了解决建议, 希望能够对建筑工程行业的稳步健康发展有所帮助。

[关键词] 建筑工程; 施工质量; 管理; 控制

DOI: $10.33142 /$ ec.v3i6.2071

中图分类号: TU712.3

文献标识码: A

\section{Discussion on Quality Management and Control of Construction Engineering}

LIU Shouyong

Beijing Construction Engineering Group Co., Ltd., Beijing, 100055, China

\begin{abstract}
Under the influence of the rapid development of society, all industries in China have made remarkable progress and development, thus promoting the improvement of China's comprehensive national strength, which brings good opportunities for China's urbanization construction. As far as the actual situation of China's urbanization construction work is concerned, the most prominent feature is the gradual transfer of rural personnel to the city, which intensifies the pressure of urban housing. In order to better meet people's demand for housing, a large number of construction projects come into being, and the construction engineering structure is moving towards a large-scale, comprehensive direction. At the same time, people's life quality and life concept have also changed significantly, people put forward higher requirements for the quality of construction projects. But in terms of the actual situation of construction engineering construction, most of the construction units in order to pursue more economic benefits, often choose the construction mode with low cost and high construction efficiency, which is very unfavorable for the guarantee of construction quality of construction engineering, so we also need to strengthen the implementation of construction project quality management and control work. This article mainly focuses on the quality management and control of construction engineering to carry out a comprehensive and in-depth study and analysis, and puts forward solutions to various problems, hoping to help the steady and healthy development of the construction industry.
\end{abstract}

Keywords: construction engineering; construction quality; management; control

引言

社会经济水平的不断提升, 为城市化建设工作的全面开展创造了良好的基础, 从而也为建筑工程建设工作整体水 平的提升起到了积极的推动作用。但是就建筑工程行业快速发展的过程中, 因为大量的建筑工程的出现, 导致当下建 筑工程管理工作无法满足社会发展的需要, 在组织开展建筑工程施工工作的过程中也遇到了诸多的阻碍, 这样对于整 个建筑工程行业的稳步健康发展是非常不利的。鉴于此, 我们需要针对整个建筑工程行业内所存在的各类问题进行综 合分析研究, 特别要关注建筑工程管理水平和施工质量控制工作, 综合各方面实际情况来制定出切实可行的工作计划, 增强建筑工程企业自身综合能力，保证企业能够在严峻的竞争形势中长期处在不败的境地。

1 建筑施工工程的质量管控现状

首先, 对建筑施工材料以及施工机械设备的质量管控工作不到位, 现如今我国建筑工程各项监理机制以及相关制 度并没有达到完善的状态, 再加上人们对施工材料以及机械设备的管理工作的忽视, 从而造成施工材料与机械设备的 质量无法满足实际施工的需要, 使得大量的质量低劣的材料被使用到建筑工程施工工作之中, 这样就会对建筑工程施 工质量产生不良影响。建筑工程具有复杂性, 综合性的特征, 所以对建筑工程施工技术水平要求较高。而当前建材市 场内部的管理机制较为缺失, 管理工作整体效果较差, 那么就会导致大量的假冒伪劣的产品流入到市场之中, 这样对 于整个建材质量的良好发展就会造成诸多的限制。 
其次, 施工管理工作人员缺少正确的施工质量认知, 建筑工程建设工作的开展是需要多个部门通力协作共同完成 的, 而各个部门之间对于利益的需求是存在一定的差别的, 这样就会导致各个部门参与工作的积极性也会存在一定的 差异。工程管理工作缺少良好的规范性, 监督和管理理念相对较为落后, 工作人员不具备完善的施工质量认知能力, 都会影响到工程质量监管工作的效率和效果。质量管理与控制工作如果不能切实的加以落实, 那么必然会对建筑工程 施工质量造成一定的损害, 工程施工管理工作效果较差, 很多施工技术工作人员技术操作不达标, 工程施工与设计方 案整体效果较差, 材料质量没有达到规定的要求标准, 都会导致工程施工过程中会存在诸多的质量隐患, 如果不能加 以切实的解决最终就会导致严重的不良后果发生。[2]

第三，施工材料采买工作人员在采购过程中不占主导地位，很多原材料的采购无法直接决策，导致各种因素影响 设备及材料的采购质量。

最后，部分施工设备性能较差，施工现场如果设备管理不到位，也会影响到整体的工程施工质量。

\section{2 建筑工程管理中的质量管理及控制对策}

\section{1 健全施工质量管控制度}

在社会快速发展的带动下, 使得人们对建筑工程质量制定了更高的标准要求, 为了从根本上对工程施工质量加以 保证, 需要施工工作人员充分结合各方面实际情况对施工管理机制进行优化和创新, 并且对施工质量管控体系进行不 断的完善, 一直从工程前期准备工作到工程建造完成的验收阶段, 都需要加大力度针对建筑工程施工质量进行监督和 管控, 切实的遵照规范标准针对工程质量实施全面监督和审核, 确保建筑工程施工质量管理体系和制度能够满足实际 工程施工需要, 依据相关质量标准对工程施工质量进行综合评价, 这样才能保证建筑工程各个施工工序能够按照既定 的计划按部就班的进行, 确保工程施工质量能够达到急性的标准要求。

\section{2 构建工程施工质量的目标责任制}

建筑工程施工工作涉及到诸多的施工工序, 所以工程施工工艺的整体水平, 施工管理工作效果往往都与建筑工程 施工质量管理和控制工作的落实存在一定的关联。建筑工程具有良好的综合性和整体性, 要想确保建筑工程质量的不 断提升, 那么最为关键的就是需要充分结合工程管理制度, 创设工程施工质量管理以及控制目标责任制度, 将建筑工 程施工质量管理职责进行详细的划分, 保证真正的落实到人头, 提升工作人员对施工质量管理以及控制职责的认知, 确定建筑工程施工任务, 将管理职责进行细致的安排, 依据建筑工程相关法律条款以及工程施工质量监督和管理实际 需要, 创设切实可行的工程施工质量目标责任制, 从多个角度进行综合考虑分析, 增强建筑工程施工全过程监督管理 力度, 充分的将权益、利益和职责加以融合, 确定工程质量监管目标, 全面的落实各项管理制度, 从根本上规避工程 施工过程中出现任何的违规操作问题。

\section{3 加强施工管理人员的素质和能力提升}

经过分析研究我们发现, 建筑工程施工管理工作人员专业能力较差以及综合素质低下的问题是当前建筑工程行业 内最为突出的问题。所以, 建筑工程施工单位务必要加大力度落实管理工作。如果管理工作的效果较差, 那么必然会 对工程施工工作的有序开展造成严重的阻碍, 再加上缺少专门的管理机制, 所以必然会引发诸多不良情况对建筑工程 工程施工质量造成一定的损害。最后是施工工作人员专业能力较差也不利于建筑工程施工质量的保证, 只有施工工作 人员具备良好的专业素质才能从根本上确保建筑工程的整体施工质量。工程施工管理工作人员的工作能力也与工程施 工质量存在一定的关联, 所以建筑施工单位需要针对管理工作人员进行专门的培训工作, 从整体上提升管理工作人员 的整体水平，从而提升管理工作的效率和效果，促进各项施工管理工作能够按照既定的计划按部就班的进行。 ${ }^{[3]}$

\section{4 加强施工材料与设备的管理力度}

一个完整的建筑工程往往需要使用到大量的不同类型的工程施工材料, 所以建筑工程材料质量往往都会与房屋建 筑施工质量密切相关, 所以为了保证建筑工程施工质量, 那么务必要对工程施工材料的监管工作给予重点关注。首先, 相关行政机构需要利用有效的方式方法对建筑材料市场秩序进行管控, 从而有效的提升执法效率和效果, 针对那些质 量低劣的施工材料需要进行有效的处理, 而对于生产质量低劣建筑材料的生产商需要给予严格的惩处, 这样才能保证 建筑施工材料质量能够达到规定的标准。其次, 施工单位需要针对所有的运送到施工现场的建筑材料质量进行抽样检 查工作, 只有保证质量无误的基础上方能加以施工运用, 一旦发现施工材料存在任何的只来那个问题, 都需要立即与 生产厂家进行调换。最后, 要充分的结合各方面实际情况来挑选恰当的检查和监管方式, 创设专门的建筑材料制定管 理责任制度, 提升施工人员的建筑材料质量管理意识, 保证建筑工程施工质量。 ${ }^{[4]}$ 此外, 要加强施工机械设别的维护与 管理, 保障机械设备的稳定运行, 确保施工过程中设备的完好性, 避免设备出现故障影响施工质量鱼施工安全。

\section{结语}

总的来说, 我国建筑工程行业正处在飞速发展的阶段, 但是整个建筑工程行业内部还存在诸多的问题, 所以我们 需要加大力度推进建筑工程行业的发展, 借助有效的方式方法促进建筑工程施工效率和质量的提升。

\section{[参考文献]}

[1] 于泳.建筑施工工程质量管理与控制措施剖析 [J]. 住宅与房地产, 2017 (06) : 186.

[2] 苏婉芳.试论建筑施工工程的质量管理与控制 [J]. 江西建材, 2016 (05) : 297-300.

[3]间兵. 建筑施工工程质量管理与控制措施剖析 [J]. 江西建材, 2016 (02) : 271-273.

[4] 白冰. 论建筑施工工程的质量管理与控制 [J]. 现代管理科学, 2003(12): 106-108.

作者简介: 刘守勇 (1990-), 男, 河北唐山人, 汉族, 大学本科学历, 工程师, 研究方向为建筑工程。 